\title{
The Theoretical Explanation of University Interdisciplinary Research Organization Collaborative Innovation: an Overview from Multiple Theory Perspectives
}

\author{
Bi Ying \& Yang Liansheng \\ Higher Education Research Center, Faculty of Humanities and Social Sciences, Dalian University of \\ Technology, Dalian, China
}

\begin{abstract}
The collaborative innovation of university interdisciplinary research organization is the historical mission of the university which higher education endow it, is the real needs of social development and cultural heritage, but also is inevitable choice, it could promote a seamless connection between university knowledge innovation and industry technology innovation to play social service functions of universities. Taking the synergetics, knowledge triangle, transaction costs and resource dependence theory perspective, this paper analyses the collaborative innovation of university interdisciplinary research organization from multiple theory perspectives, expect to provide experience enlightenment for the theoretical construction of I-U-R collaborative Innovation.
\end{abstract}

KEYWORD: university interdisciplinary research organization; knowledge creation; technological innovation

\section{INTRODUCTION}

What is the collaborative innovation of university interdisciplinary research organization? Why form partnerships? What is the best collaborative innovation model? These issues need a theoretical explanation. Taking the synergetics, knowledge triangle, transaction costs and resource dependence theory perspective, this paper attempts to describe and explain the generation, motivation, patterns and mechanisms of collaborative innovation of the university interdisciplinary research organization. The preliminary exploration is constructing the theoretical basis development of collaborative innovation of the university interdisciplinary research organization.

\section{THE COLLABORATIVE INNOVATION OF UNIVERSITY INTERDISCIPLINARY RESEARCH ORGANIZATION: THE NATURE OF COLLABORATIVE INNOVATION OF UNIVERSITY INTERDISCIPLINARY RESEARCH ORGANIZATION FROM THE SYNERGETIC THEORY PERSPECTIVES}

What is the synergetic theory? The synergetic theory is a branch of the system scientific theories. In 1971, the German scholar Haken first proposed the concept of synergy in the system theory, referring to the coordinated system of each subsystem, cooperation or joint action and collective behavior synchronization, resulting in a synergistic effect, namely $1+1>2$. The means are, within a system, if each subsystem can not collaborative work well together, even against each other, mutual restraint, such a system must exhibit disordered state, and therefore can not play the overall function and eventually collapse. Conversely, if the system can be a good fit for each subsystem, collaborative, multi-force will be able to gather into a total force, achieve to the new functions which far beyond the sum of the original individual functions (Xue Chuanhui, 2012).

So, what mean is "collaborative innovation". Collaborative innovation, which earliest given by Peter Gloor (2005) from MIT, is defined as "a cyberteam of self-motivated people with a collective vision, enabled by the Web to collaborate in achieving a common goal by sharing ideas, information, and work." Delphine Gallaud thinks (2013) Collaborative innovation is the fact that an organization cooperates with other firms (suppliers, customers, competitors, and consultants) or other organizations (such as universities or public research organism) to develop or commercialize a new innovation.

In China, Yan Xiong (2007) proposed "I-U-R collaborative innovation refers to the collaborative innovation activities of three basic bodies between industries, universities, and research institutes, they put their superior resources and capabilities, under collaborative support of the government, technology services agencies, financial institutions and other related subjects."

Another scholar for the purposes of the same innovators proposed collaborative innovation is the knowledge (ideas, expertise, technology) sharing mechanism the organization (enterprise) inside 
formed more and more, the participants sharing a common goal and intrinsic motivation direct communicate rely on modern IT and building resource platform for multi-directional communication, diverse collaboration (Zhang, 2011).

From the perspective of synergetic theory, it was found that collaborative innovation is highlighted in a complex system, collaborative behavior of each subsystem produces an effect beyond their own individual role of each element and form the role of an unified and the joint action in the whole system.

According to the above definitions and comparing with cooperation innovation, "collaborative innovation" have many innovative alliances, through sharing ideas, knowledge, expertise and opportunities, the main barriers between human, financial, material, information and organization could be broken through, the depth of collaboration could be carried out. Knowledge and expertise sharing can achieve value creation which can be used in the reaching of a common goal.

According to the strategic research, that the country need cutting-edge areas of S\&T for major issues and the researches related to the national economy and the common goal of public welfare, put them into their superior resources and capabilities, support government contribution, science and technology intermediary service organizations, financial institutions and other related subjects. University interdisciplinary research organization and many innovative alliances achieve collaborative innovation by building innovative platforms, shared resource information and technological cooperation.

From the theoretical point perspectives, the collaborative innovation of university interdisciplinary research organization should explore the issues in which the university interdisciplinary research organization is consistent with the dominant and many innovative alliances, it should develop collaborative innovation and achieve collaborative innovation. Collaborative innovation of this study is mainly comes from the micro-level studies. Its essence is the integration of different types of innovation subject, based on a common goal, break the barriers of a variety of institutional mechanisms between the elements of innovation, reach really a sharing of resources, generate synergies process which alone elements can not be achieved.

\section{THE COLLABORATIVE INNOVATION OF UNIVERSITY INTERDISCIPLINARY RESEARCH ORGANIZATION: THE DYNAMIC MECHANISM OF KNOWLEDGE INNOVATION FROM KNOWLEDGE TRIANGLE THEORY PERSPECTIVES}

The knowledge triangle is a concept that refers to the integration of research, education and innovation. The concept of knowledge triangle goes one step beyond merely acknowledging the relevance of $R \& D$, education and innovation: not only are these policy areas important, but there are important positive externalities between them (Soriano \& Mulatero, 2010).

From the knowledge triangle ecosystem diagram can be found between education, research and development, the importance contribution of education to research is already widely acknowledged: R \& D needs to train highly skilled personnel through education. Meanwhile, the R\&D activities can also contribute to the development of education.

The knowledge triangle highlights the importance of paying an equal attention to the integration of cutting-edge research output into education. Between innovation and education, the importance contribution of education to innovative demand is uncontroversial: the highly educated consumer is really the first adopters of innovative products and services. The quantity and quality of education has played a key role for the promotion of innovation. Highly skilled workers must be innovative activities. When the entire staff has a good educational foundation and proper training, they can more easily adapt and use innovative production process.

Knowledge triangle also recognizes that innovation can in turn generate impact on the education system, not only by providing new technologies and new media content, but also by improving the learning environment. Between R\&D and innovation, when the production of new knowledge and new technologies create new products through transfer to industry, the benefits of new products will carry out further $\mathrm{R} \& \mathrm{D}$, and promote new knowledge (technology) transfer. Knowledge triangle ecosystems make the interaction and mutual influence between education, research and innovation in three areas, so as to achieve effective integration.

Formed as an independent unit within the university, the university interdisciplinary research organization broke the organizational boundaries of disciplines and departments, directly in charge of the vice president of research in universities, developed innovative collaboration through interdisciplinary research. Therefore, in the university interdisciplinary research organizations, the intellectual activities were expressed as knowledge dissemination, knowledge production and knowledge transfer between education, research and innovation.

When the various elements of the three knowledge areas interacting with each other, it will achieve twoway flow between education, research and innovation. The functions of knowledge production, knowledge dissemination and knowledge transfer within the university interdisciplinary research organization are achieved at the same time.

In the "knowledge triangle", the university interdisciplinary research organization is an important subject of collaborative innovation, which the essential attribute is the process of management 
innovation, is the process of knowledge production, knowledge dissemination and knowledge transfer within university interdisciplinary research organization and many innovative alliances.

In the chain of the knowledge production-the knowledge dissemination-the knowledge transfer, the independence $R \& D$ of university interdisciplinary research organization is not realistic, need to cooperate between research institutes, enterprises, carry out collaborative innovation.

Therefore, because of a common goal, university interdisciplinary research organizations and many innovative alliances need to come together, and integrate innovative resources and different elements, such as personnel, intelligence, capital, information, technology, breakthrough innovation barriers and achieve new knowledge production, knowledge dissemination and knowledge transference. The need to innovate operation mode, not only requires the depth integration of the university collaborative interdisciplinary research organizations and other synergies, but also requires innovation between goals, organization, systems and the environment, the integration of different innovative elements and the realization of knowledge value, which requires the total factor of collaborative innovation release on each node in the chain of knowledge productionknowledge dissemination-knowledge transfer, formate a new driving force, namely knowledge value.

\section{THE COLLABORATIVE INNOVATION OF UNIVERSITY INTERDISCIPLINARY RESEARCH ORGANIZATION: THE BEST MODEL OF COLLABORATIVE INNOVATION IS SELECTED FROM TRANSACTION COST THEORY PERSPECTIVES}

What are the transaction costs? The concept was first advocated by Coase. R. in "the Nature of the Firm", Coase (1937) appointed that transaction cost is the cost of using the market. Correspondingly, there are costs of using firms. When the costs of using the organization are greater than the costs of using the market, the firm would turn to market transactions to avoid internal costs.

In the 1960, in an article of "social costs", the contents of transaction costs was more clearly defined: including the costs of discovery and notificate traders, negotiation costs, signing contracts and the necessary inspection costs guarantee the performance of the contract terms. Transaction costs can be divided into three broad categories: the first, search and information costs are costs such as those incurred in determining that the required good is available on the market, which has the lowest price, etc. the second, Bargaining costs are the costs required to come to an acceptable agreement with the other party to the transaction, drawing up an appropriate contract and so on. In game theory this is analyzed for instance in the game of chicken.

At least two definitions of the phrase "transaction cost" are commonly used in literature. Transaction costs have been broadly defined by Steven N. S. Cheung (1987) as any costs that are not conceivable in a "Robinson Crusoe economy"- in other words, any costs that arise due to the existence of institutions. For Cheung, if the term "transaction costs" were not already so popular in economics literatures, they should more properly be called "institutional costs".

According to Williamson, the determinants of transaction costs are frequency, specificity, uncertainty, limited rationality, and opportunistic behavior (Williamson, Oliver E., 2002).

The collaborative innovation of university interdisciplinary research organization requires to achieve the depth of cooperation around a common goal between university interdisciplinary research organizations and main innovative alliances, to achieve efficient resource sharing, promote the formation of synergies. Therefore, the selection of right collaborative innovation model is very important.

In order to study on the I-U-R collaborative innovation model, we need to clarify the type of I-U-R cooperation model, generally including patent licensing, technology transfer, R\&D cooperation. A research and development entity organization also needs to be built. The trading partners of cooperation contracts are knowledge products or knowledge services. Therefore, the transaction cost theory provides a good research perspective. Hong Yinxing (2014) thinks that the key of I-U-R collaborative innovation was the process of scientific findings and innovative research and innovative knowledge incubate new technology.

From the perspective of transaction cost savings, the motivation which companies involved in the collaborative innovation of university interdisciplinary research organization is reduce the uncertainty of technological innovation process and the excess costs. When the internal $R \& D$ risks and costs in companies is more than I-U-R collaborative innovation, companies will choose to conduct collaborative innovation with universities and research institutions. The transaction frequency is high, the cooperation understanding is slow, the information is relatively symmetrical, the mutual trust is large. All these can reduce the information search costs and the occurrence of the opportunistic behavior. If the transaction frequency is low, the cooperation understanding is less, the information is not symmetrical, and then the mutual trust will be low for each other.

Long-term contracts will encourage the collaborative innovation subjects to consider the cooperation from the long-term interests, which would select a good cooperation model, from market transactions to build a solid $\mathrm{R} \& \mathrm{D}$ cooperation, so 
collaborative innovation subjects will be able to save transaction costs, achieve synergy and innovation.

\section{THE COLLABORATIVE INNOVATION OF UNIVERSITY INTERDISCIPLINARY RESEARCH ORGANIZATION: THE IMPLEMENTATION PROCESS OF KNOWLEDGE PRODUCTION AND KNOWLEDGE TRANSFER FROM RESOURCE DEPENDENCE THEORY PERSPECTIVES}

In 1978, American scholar Jeffrey Pfeffer and Gerald Salancik (1978) co-published the book title "External control organizations: the resource dependency analysis", comprehensively explain on the resource dependence theory, made a huge academic contributions. The resource dependence theory considered that anyone organization can not be selfsufficient, are exchanged with the environment through continuous access to resources from the environment and obtain the survival and development.

It can found, the organization must access to win resources from the outside world in order to survive and development, which led to the organization's dependence on outside resources. Meanwhile, the theory considered that all organizations are committed to improving their dependence on other organizations, namely through access to and control of key resources to reduce dependence on external resources. To achieve the goal, any one organization and other organizations which control the appropriate resources must interact, and thus to obtain the necessary resources.

As the concept's definition shows, the concept of collaborative innovation within university interdisciplinary research organization is in the line of the resource dependence theory to explain the organization's objectives and reveal the organization's dependence on the outside world. It stressed the importance of the complementary resources. Therefore, the application of resource dependence theory which explain the collaborative innovation of university interdisciplinary research organization is a certain rationality, which provides a theoretical basis to analysize the collaborative innovation of university interdisciplinary research organization.

The success of collaborative innovation within university interdisciplinary research organization is affected by many factors, which play a decisive role in innovation resources. New resources of the collaborative innovation of university interdisciplinary research organization rely in the following three aspects:

The first is the resources integration. The collaborative innovation of university interdisciplinary research organization has become inevitable because of competitive environment and complementary resources. In the process of collaborative innovation, the enterprises participate in collaborative innovation.
Research and development capabilities, new knowledge, and potential production in university meet the needs of enterprise technology innovation. Various collaborative innovators will obtain complementary resources and achieve resources sharing.

The second is the creation of new knowledge. The important function of universities is to make knowledge innovation, but also an important source of technological innovation. In the process of collaborative innovation, according to the needs of industry, university interdisciplinary research organization will integrate the main collaborative innovation resources, scientific knowledge and technology effectively, participate to the production of new knowledge in line with industry needs, achieve synergies.

The third is the knowledge exchange. When universities and research institutes could promote the new knowledge production which industry needed to achieve the knowledge innovation through collaborative innovation.

\section{ACKNOWLEDGEMENTS}

This work is partially supported by funding from National Natural Science Foundation of China grants (Project Grant Number: 71240010) in 2012.

\section{REFERENCES}

[1] Cheung, Steven N. S. 1987. Economic organization and transaction costs. The New Palgrave: A Dictionary of Economics. (2): 55-58.

[2] Delphine Gallaud.2013. Collaborative Innovation and Open Innovation.Encyclopedia of Creativity, Invention, Innovation and Entrepreneurship: 236-241.New York: Springer Science Business Media, LLC.

[3] Fernando Hervás Soriano \& Fulvio Mulatero.2010. Knowledge Policy in the EU: From the Lisbon Strategy to Europe 2020.J Knowl Econ. (1): 289-302.

[4] Hong Yinxing.2014. Economic Analysis of I-U-R collaborative innovation. Economic Science (1):56-64.

[5] Miles, R.E., Snow, C.C., Miles, G.2005. Collaborative entrepreneurship: how communities of networked firms use continuous innovation to create economic wealth. Stanford University Press.

[6] Peter Gloor. 2005. Swarm Creativity: Competitive Advantage through Collaborative Innovation Networks.

[7] Pfeffer,J \& Salancik, G.1978.The external control of organizations: A Resource Dependence Perspective.New York: Harper\& Row Fublishers.

[8] R. H. Coase.1937. The Nature of the Firm. Economica, 16(4):386-405.

[9] Williamson, Oliver E.2002. The Theory of the Firm as Governance Structure: From Choice to Contract, Journal of Economic Perspectives 16(3):171-195.

[10] Xue chuanhui. 2012. Study on the collaborative innovation strategy of universities and colleges. Contemporary Educational Science (7):29-31.

[11] Yanxiong.2007. Five research collaborative innovation issues must be tackled. China High-Tech Industry Review. 